\title{
Prediction of caesarean section for labor dystocia in women with full-term single pregnancy with head presentation of the fetus
}

\author{
Olga Grishchenko, Sevindzh Mamedova \\ Department of Perinatology, Obstetrics and Gynecology \\ Kharkiv Medical Academy of Postgraduate Education, Kharkiv, Ukraine
}

\begin{abstract}
The actual problems of modern obstetrics are the labor management and a decrease of emergency caesarean section's frequency.

The aim of the study was to optimize the definition of indications for abdominal delivery by determining risk factors and forecasting on the basis of clinical and anamnestic indicators.

A retrospective clinical and statistical analysis of pregnancy and childbirth histories of 484 mothers -65 women in which labor was complicated by labor dystocia (LD) and caesarean section (CS) and 419 women after vaginal labor was performed.

Three factors had the greatest dependency with CS for LD: burdened gynecological anamnesis (OR 21.134; 95\% Cl 6.501-68.708); diabetes mellitus (OR - 19.462; 95\% Cl 5.018-75.485) and fetal-pelvic disproportions (OR - 11.556; 95\% Cl 2.692-49.595). Genital tract infections, primiparous and cardiovascular diseases had OR more than 5.0. OR was greater than 3.0 in hypertension, preeclampsia, premature rupture of amniotic membranes, and late reproductive age.

Conclusions. The greatest influence on the likelihood of CS for LD is observed in premature rupture of amniotic membranes, diabetes mellitus, burdened gynecological history and cardiovascular diseases in the primiparous of late reproductive age.
\end{abstract}

Keywords: labor dystocia, caesarean section, risk factors, odds ratio, predicting

\section{INTRODUCTION}

Even in large perinatal centers equipped with high-tech equipment, in women with some somatic pathology, anatomical and physiological features, the opportunity to have a child may be only by cesarean section (CS) [1,2]. CS in combination with new technologies of observation and treatment allows, even in the presence of contraindications, to plan a pregnancy and give birth to a child with minimal risk of maternal complications and perinatal losses [3]. But in recent years, scientists and health care providers have been concerned about the steady increase of CS frequency. For example, in the United States in 1970, only 5\% of women gave birth by CS, and in 2016-31.9\% [4]. In Australia, the incidence of CS in the first birth reaches $29.1 \%$ (18.2\% - urgent, $10.2 \%$ - planned) [5], in Canada $-27.1 \%$ [6], in China - 34.9\% [ 7], and in Egypt
52\% [8]. In addition, according to the American College of Obstetricians and Gynecologists and the Society for Maternal-Fetal Medicine, there is a significant difference in the frequency of CS between individual hospitals - from $7.1 \%$ to $69.9 \%$. This indicates that there are significant differences between existing approaches to determine the indications for CS, which requires correction [9]. Many researchers attribute this trend to subjective factors, including the unreasonable expansion of indications for operative delivery and the reluctance of the physician or patient for vaginal labor [8]. In addition, the number of "non-medical" factors in the structure of indications for CS significantly increases $[10,11]$.

The presence of indications of CS, carried out in a planned manner, prevents complications of childbirth. But emergency CS significantly increases the 
risk of complications for the mother and fetus. According to an analysis by the US National Institute of Health, a caesarean section increases the risk of severe complications from $0.9 \%$ to $2.7 \%$, including severe bleeding, uterine rupture, anesthesia complications, shock, cardiac arrest, acute renal failure, thromboembolism, infections, hematomas and wound complications [9].

One of the common causes of emergency CS is the labor dystocia (LD). The incidence of emergency $\mathrm{CS}$ in prolonged induction of labor due to $\mathrm{LD}$ was 57\% [13]. Optimizing the childbirth management is one of the promising areas for improving perinatal outcomes.

\section{AIM}

The aim of the study was to optimize the definition of indications for abdominal delivery by determining risk factors and forecasting on the basis of clinical and anamnestic indicators.

\section{MATERIAL AND METHODS}

The study was performed on the clinical bases of the Department of Perinatology, Obstetrics and Gynecology of the Kharkiv Medical Academy of Postgraduate Education. A retrospective clinical and statistical analysis of pregnancy and childbirth histories of 484 mothers was performed. Criteria for inclusion in the study were: full-term (gestational age from 37 weeks and more) single pregnancy; the head presentation of the fetus; no scar on the uterus (caesarean section and/or other operations on the uterus). Women with pregnancies resulting from assisted reproductive technologies were not included in the study.

Women were divided into two groups: group I -65 women in which labor was complicated by LD and CS; group II (comparison) - 419 women after vaginal labor. The design of the study was reviewed by the Ethics Commission of the Kharkiv Medical Academy of Postgraduate Education at the planning stage of the study and recognized as compliant with international and Ukrainian legal and ethical standards.

The analysis of clinical and anamnestic data depending on the presence of LD used descriptive statistics, Fisher's exact criterion and calculation of the odds ratio (OR) and its $95 \%$ confidence interval (CI).

Regression analysis was performed to create a prognostic model. The analyzed factors were coded in the form of a nominal scale (no - " 0 ", there is "1"), followed by statistical processing by binary logistic regression (BLR). The dependent variable was CS in women with LD (yes, no); clinical and qualitative clinical and anamnestic parameters were accepted as independent variables.

The assessment of the prognostic value was performed based on the calculation of the sensitivity and specificity of the model in the ratio of true and false positive and negative predictions. The quality of the model was checked using ROC analysis to determine the area under the ROC curve (AUC).

The calculations were performed using the PSSP statistical software package (an open program that does not require a license).

\section{RESULTS}

To determine the most influential factors from the available clinical and anamnestic indicators, first of all, frequency analysis was performed (table 1). It turned out that in mothers whose childbirth was complicated by LD, which was the cause of CS (group I), most of the indicators that were able to negatively affect the course of labor were significantly more common.

TABLE 1. Frequency of clinical and anamnestic parameters in women in labor included in the study

\begin{tabular}{|l|c|c|c|}
\hline Indicators & $\begin{array}{c}\text { group I - } \\
\text { main } \\
\text { (n= 65) }\end{array}$ & $\begin{array}{c}\text { group II } \\
\text { (comparison) } \\
\text { (n = 419) }\end{array}$ & $\mathbf{p}^{\mathbf{1}}$ \\
\hline Primiparous & $58(89.2 \%)$ & $249(59.4 \%)$ & $<0.001$ \\
\hline $\begin{array}{l}\text { Premature rupture of } \\
\text { amniotic membranes }\end{array}$ & $22(38.8 \%)$ & $51(12.2 \%)$ & $<0.001$ \\
\hline $\begin{array}{l}\text { Burdened gynecological } \\
\text { history }\end{array}$ & $11(16.9 \%)$ & $4(1.0 \%)$ & $<0.001$ \\
\hline Genital tract infections & $7(10.8 \%)$ & $8(1.9 \%)$ & 0.002 \\
\hline $\begin{array}{l}\text { Fetus-pelvic } \\
\text { disproportions }\end{array}$ & $5(7.7 \%)$ & $3(0.7 \%)$ & 0.002 \\
\hline Preeclampsia & $5(7.7 \%)$ & $8(1.9 \%)$ & 0.020 \\
\hline Large fetus & $7(10.8 \%)$ & $20(4.8 \%)$ & 0.074 \\
\hline Late reproductive age & $14(21.5 \%)$ & $34(8.1 \%)$ & 0.003 \\
\hline Diabetes mellitus & $8(12.3 \%)$ & $3(0.7 \%)$ & $<0.001$ \\
\hline Cardiovascular disease & $11(16.9 \%)$ & $16(3.8 \%)$ & $<0.001$ \\
\hline Hypertension & $9(13.8 \%)$ & $14(3.3 \%)$ & 0.001 \\
\hline Obesity & $8(12.3 \%)$ & $19(4.5 \%)$ & 0.019 \\
\hline Endocrine diseases & $10(15.4 \%)$ & $32(7.6 \%)$ & 0.055 \\
\hline
\end{tabular}

Note 1 - the significance of the difference between the groups on the bilateral Fisher's exact test

Significantly more often $(\mathrm{p}<0.05$ according to Fisher's exact test) in the main group were primiparous (89.2\% vs. 59.4\%), premature rupture of amniotic membranes $(38.8 \%$ vs. $12.2 \%)$, burdened gynecological history $(16.9 \%$ vs. $1.0 \%)$, genital tract infections $(10.8 \%$ vs. $0.7 \%)$, fetus-pelvic disproportions $(7.7 \%$ vs. $0.7 \%)$, preeclampsia $(7.7 \%$ 
vs. $1.9 \%)$, late reproductive age (21.5\% vs. $8.1 \%)$, diabetes mellitus $(12.3 \%$ vs. $0.7 \%)$, cardiovascular disease (16.9\% vs. $3.8 \%)$, hypertension (13.8\% vs. $3.3 \%$ ), obesity ( $12.3 \%$ vs. $4.5 \%)$. Large fetus and endocrine diseases were more common, but not statistically significant in the main group.

Thus, most of the analyzed indicators were significantly more common in the main group of women, which indicates their possible role as risk factors for CS for LD. To clarify the impact of indicators that were significantly increased in women of the main group, we made the analysis of OR of the development of LD that requires CS (table 2).

TABLE 2. The OR of $L D$ that requires CS, depending on the presence of certain clinical and anamnestic indicators

\begin{tabular}{|l|c|c|c|}
\hline \multirow{2}{*}{ Indicators } & \multirow{2}{*}{ OR } & \multicolumn{2}{|c|}{ 95\% Cl } \\
\cline { 3 - 4 } & & Lower limit & Upper limit \\
\hline $\begin{array}{l}\text { Burdened gynecological } \\
\text { history }\end{array}$ & 21.134 & 6.501 & 68.708 \\
\hline Diabetes mellitus & 19.462 & 5.018 & 75.485 \\
\hline Fetus-pelvic disproportions & 11.556 & 2.692 & 49.595 \\
\hline Genital tract infections & 6.200 & 2.168 & 17.736 \\
\hline Primiparous & 5.474 & 2.304 & 13.007 \\
\hline Cardiovascular disease & 5.131 & 2.263 & 11.632 \\
\hline Hypertension & 4.649 & 1.923 & 11.240 \\
\hline Preeclampsia & 4.281 & 1.356 & 13.517 \\
\hline $\begin{array}{l}\text { Premature rupture of } \\
\text { amniotic membranes }\end{array}$ & 3.692 & 2.044 & 6.669 \\
\hline Late reproductive age & 3.108 & 1.563 & 6.182 \\
\hline Obesity & 2.955 & 1.236 & 7.063 \\
\hline Large fetus & 2.408 & 0.975 & $5.944^{1}$ \\
\hline Endocrine diseases & 2.199 & 1.024 & 4.721 \\
\hline
\end{tabular}

Note 1 - The result is not statistically significant.

The value of OR reflects the relationship of a particular risk factor with a particular event (in our case, it is CS for LD). The value of OR for all indicators exceeds 1.0, which indicates an increase in the chances of CS in the presence of any of these indicators. In one indicator (large fetus) the lower limit of CI is less than 1.0, the upper - more than 1.0 , that indicates a statistical inaccuracy of the results $(p>0.05)$. All other indicators had a statistically significant value of OR (table 2).

Three factors had the greatest dependency with $\mathrm{CS}$ for LD: burdened gynecological anamnesis (OR - 21.134; 95\% CI 6.501-68.708); diabetes mellitus (OR - 19.462; 95\% CI 5.018-75.485) and fetal-pelvic disproportions (OR - 11.556; 95\% CI 2.692-49.595). The OR was quite high in genital tract infections, primiparous and cardiovascular disease (OR more than 5.0). OR was greater than 3.0 in hypertension, preeclampsia, premature rup- ture of amniotic membranes, and late reproductive age. All other indicators (obesity, large fetus and endocrine diseases) had an OR of more than 2.0.

These indicators were included in the regression analysis and the results are given in table 3 .

TABLE 3. The results of regression analysis of the probability of LD with CS (step-by-step method of inclusion of Wald - the last step)

\begin{tabular}{|l|c|c|c|c|}
\hline & B & Wald & p & Exp(B) \\
\hline $\begin{array}{l}\text { Premature rupture of } \\
\text { amniotic membranes }\end{array}$ & 1.431 & 15.898 & 0.000 & 4.183 \\
\hline Preeclampsia & 1.439 & 3.416 & 0.065 & 4.218 \\
\hline Late reproductive age & 1.682 & 11.530 & 0.001 & 5.375 \\
\hline $\begin{array}{l}\text { Fetus-pelvic } \\
\text { disproportions }\end{array}$ & 2.294 & 6.339 & 0.012 & 9.917 \\
\hline Diabetes mellitus & 2.251 & 7.828 & 0.005 & 9.495 \\
\hline $\begin{array}{l}\text { Burdened } \\
\text { gynecological history }\end{array}$ & 2.618 & 13.580 & 0.000 & 13.703 \\
\hline Cardiovascular disease & 1.664 & 8.913 & 0.003 & 5.283 \\
\hline Parity & -1.916 & 16.003 & 0.000 & 0.147 \\
\hline Constant & -0.530 & 0.872 & 0.350 & 0.589 \\
\hline
\end{tabular}

Notes: $B$-regression coefficient; $p$ - significance.

First of all, it is noteworthy that the final calculation, in addition to obstetric and gynecological indicators, included concomitant pathology: rupture of amniotic membranes (x1), preeclampsia (x2), late reproductive age (x3), fetal-pelvic disproportions (x4), diabetes mellitus (DM) (x5), burdened gynecological history (x6), cardiovascular disease (x6) and parity (x7) (table 3).

The effect of most symptoms on probability of CS for LD was significant ( $p<0.05$ ), except for the value of preeclampsia, in which the significance was lower $(p=0.065)$. The attribute "parity" - had a regression coefficient $(\mathrm{B})$ with a sign "minus": at a value of " 1 " (first childbirth) the probability increases. All other indicators had regression coefficients of positive value.

In addition, based on the value of Wald's index, in addition to parity, the most significant impact was the rupture of amniotic membranes, burdened gynecological history, late reproductive age, cardiovascular disease, diabetes mellitus, fetus-pelvic disproportions and parity. In this case, the value of the coefficient Exp (B), which is analogous of OR, proved to be the most significant in burdened gynecological history, diabetes mellitus and fetus-pelvic disproportions.

The final value $\mathrm{z}$ of the regression equation for calculating the probability of CS for LD is as follows:

$$
\begin{gathered}
z=-0.530+\mathrm{x}_{1} \cdot 1.431+\mathrm{x}_{2} \cdot 1.439+\mathrm{x}_{3} \cdot 1.682+ \\
\mathrm{x}_{4} \cdot 2.294+\mathrm{x}_{5} \cdot 2.251+\mathrm{x}_{6} \cdot 2.618+\mathrm{x}_{7} \cdot 1.664-\mathrm{x}_{8} \cdot 1.916
\end{gathered}
$$


When checking the accuracy of the forecast, the obtained results can be observed in table 4 .

TABLE 4. Table of classification of the forecast of CS for $L D$, by means of the logistic analysis

\begin{tabular}{|c|c|c|c|c|}
\hline \multirow{2}{*}{\multicolumn{2}{|c|}{ Real }} & \multicolumn{3}{|c|}{ Predicted } \\
\hline & & \multicolumn{2}{|c|}{ CS for LD } & \multirow{2}{*}{$\%$ correct } \\
\hline & & no & yes & \\
\hline \multirow{2}{*}{ CS for LD } & no & 398 & 21 & 95.0 \\
\hline & yes & 34 & 31 & 47.7 \\
\hline \multicolumn{2}{|l|}{ Total \% } & & & 88.6 \\
\hline
\end{tabular}

The overall accuracy of the forecast was $88.6 \%$, the prognostic value of a negative result $-95.0 \%$, the prognostic value of a positive result $-47.7 \%$. The sensitivity of the model $-40.4 \%$; specificity $92.1 \%$.

The obtained data are confirmed by the results of ROC analysis - the value of AUC was 0.701 $(95 \%$ CI $0.621-0.781)(\mathrm{p}<0.001)$, which indicates a sufficient quality of the prognostic model (Fig. 1).

Thus, the obtained results indicate the possibility of predicting CS for LD.

\section{DISCUSSION}

Attempts to predict the course of labor and the need for CS based on the available clinical and medical history data have been undertaken by many researchers. Numerous factors are known that affect the frequency of CS, often combined into com- plex prognostic models. So, in the complex predictive model, Danilack et al. (2019) included gestational age, race, maternal age, obesity, fibroids, large fetal growth, and a history of herpes [14]. In the prognosis model of CS in women with labor induction, the risk factors for CS were older mother's age, shorter mother's height, greater body mass index, greater weight gain during pregnancy, greater gestational age, hypertension, diabetes mellitus, immature cervix (less than $3 \mathrm{~cm}$ ) [15]. According to the results of multivariate analysis, the most significant independent risk factors for emergency CS were the abnormal amniotic fluid, primiparous, induction of labor and the abnormal composition of amniotic fluid. In addition, the risk increased for mothers with a body mass index before pregnancy of more than $20.5 \mathrm{~kg} / \mathrm{m}^{2}$, with an abnormal umbilical cord and newborn weight of more than 3,550 g [16].

Also known are the results of studies on the forecasting of LD. The frequency of LD increased in the presence of diabetes mellitus [17], obesity $[18,19]$, the age of the mother [20] and other factors. In a comprehensive analysis of the study of CS risk factors after induction of single pregnancies with intact membranes and immature cervix during childbirth without a history of previous CS, the risk factors for CS were primiparous, gestational age over 40 weeks, BMI, Bishop's scale, and maternal height. A fairly high prognostic capacity was

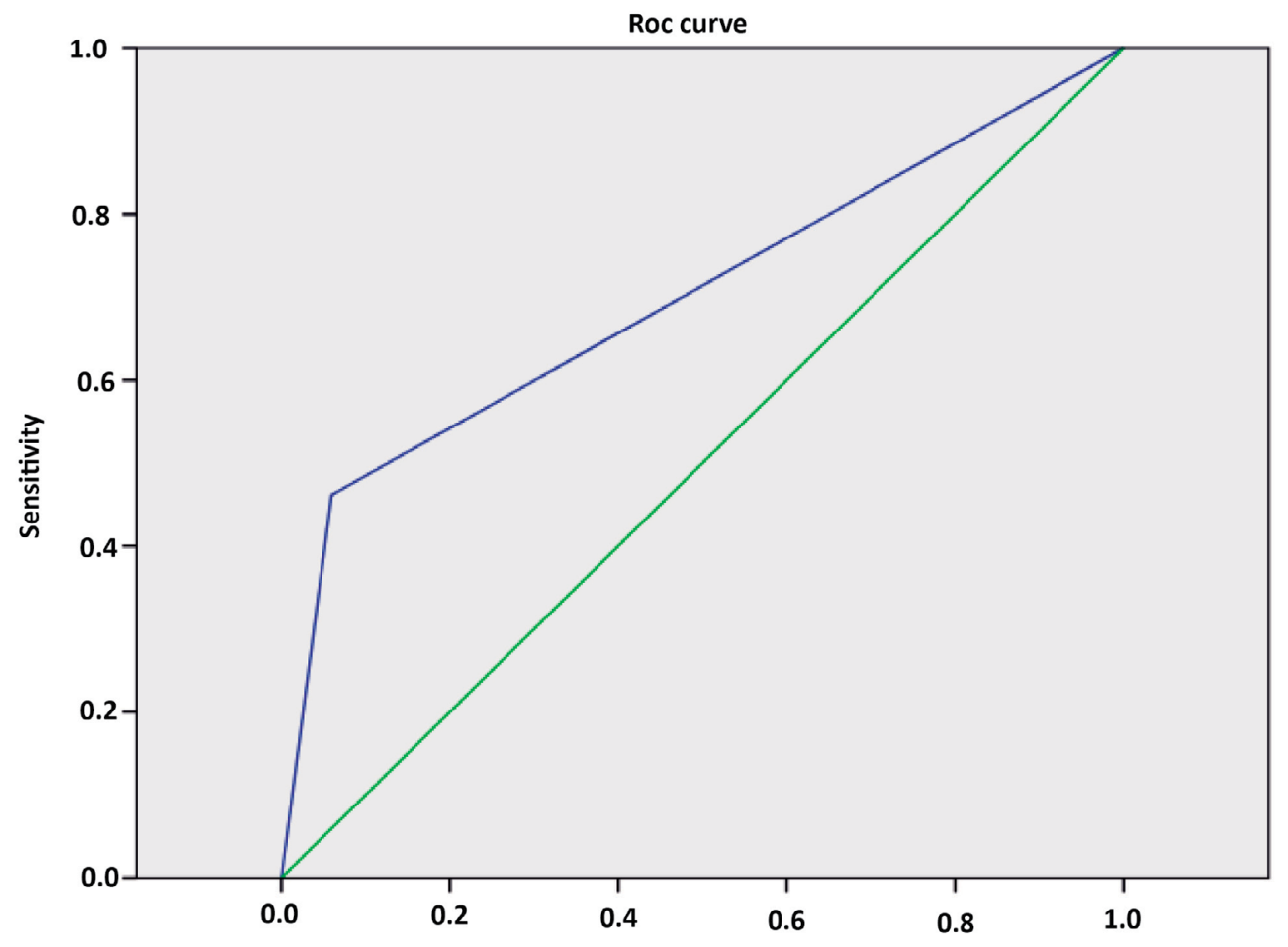

FIGURE 1. Result of ROC analysis of predicting model 
established, which was confirmed by external validation (in a sample of more than 200,000 births in 19 US department during 2002-2008) - AUC 0.73; 95\% SI 0.72-0.74 [21].

Most studies differ in inclusion criteria and analysis methods used. When creating CS forecast models, cases of operative delivery, performed in a planned manner according to traditional indications, are often included, and when forecasting LD, cases ending in vaginal labor and emergency CS are combined.

Unlike other researchers, we included in the analysis of pregnant women with full-term, single pregnancy, with a head presentation of the fetus and without a scar on the uterus, since in all these cases, CS was performed according to urgent indications, and in particular in connection with LD. As a result, the prognostic model included obstetrical and gynecological factors, which are essentially the cause of the development of LD, and additional aggravating factors that probably caused the unsuccessful stimulation of labor.

In addition, it draws attention to the fact that, despite a certain generality of the results obtained

\section{REFERENCES}

1. Ye J, Zhang J, Mikolajczyk R, et al. Association between rates of caesarean section and maternal and neonatal mortality in the 21st century: A worldwide population-based ecological study with longitudinal data. BJOG. 2016;123:745-53.

2. Gosset M, llenko A, Bouyou J, et al. Emergency caesarean section. J Visc Surg 2017;154:47-50.

3. Caesarean section: evidence update March 2013. A summary of selected new evidence relevant to NICE clinical guideline 132 'Caesarean section' (2011). London: National Institute for Health and Care Excellence; 2013. Evidence update 35; http://www.nice.org.uk/ guidance/cg132/documents/cg132-caesarean-sectionevidenceupdate2.

4. Joyce A, Martin MPH, Hamilton PD BE, Osterman MHS MJK. Births in the United States, 2016. NCHS Data Brief. 2017;287:1-8.

5. Hure A, Powers J, Chojenta C, Loxton D. Rates and Predictors of Caesarean Section for First and Second Births: A Prospective Cohort of Australian Women. Matern Child Health J. 2017;21(5):1175-1184.

6. Hobbs AJ, Mannion CA, McDonald SW, Brockway M, Tough SC. The impact of caesarean section on breastfeeding initiation, duration and difficulties in the first four months postpartum. BMC Pregnancy Childbirth. 2016:16:90.

7. Li HT, Luo S, Trasande L, et al. Geographic variations and temporal trends in cesarean delivery rates in China, 2008-2014. JAMA 2017;317:69-7.

8. Elnakib S, Abdel-Tawab N, Orbay D, Hassanein N. Medical and non-medical reasons for cesarean section delivery in Egypt: A hospital-based retrospective study. BMC Pregnancy Childbirth. 2019;19(1):411.

9. American College of Obstetricians and Gynecologists (College); Society for Maternal-Fetal Medicine, Caughey AB, Cahill AG, Guise $\mathrm{JM}$, Rouse DJ. Safe prevention of the primary cesarean delivery. Am J Obstet Gynecol. 2014;210(3):179-93. by different research groups, complete coincidences are not observed, and often the data obtained are directly opposite. In our opinion, this is due to the subjective factor - the experience of the doctor, the desire of the patient, the features of standard practice. In this regard, it is advisable to create such models taking into account local characteristics of obstetrical care.

\section{CONCLUSIONS}

The causes and risk factors for CS for LD are very diverse. Timely identification of potential risks of the complicated labor will optimize the preparation and labor management tactics.

Evaluation of the set of clinical and anamnestic factors using regression analysis allows to create a prognostic model of the likelihood of CS for LD with a total forecast accuracy of $88.6 \%$.

The greatest influence on the likelihood of CS for LD is observed in premature rupture of amniotic membranes, diabetes mellitus, burdened gynecological history and cardiovascular diseases in the primiparous of late reproductive age.

Conflict of interest: none declared Financial support: none declared

10. Mylonas I, Friese K. Indications for and risks of elective cesarean section. Dtsche Arztebl Int. 2015;112:489-95.

11. Vogel JP, Betrán AP, Vindevoghel $N$, et al. Use of the Robson classification to assess caesarean section trends in 21 countries: A secondary analysis of two WHO multicountry surveys. Lancet Glob Health. 2015;3:e260-70.

12. Davey MA, Flood M, Pollock W, Cullinane F, McDonald S. Risk factors for severe postpartum haemorrhage: A population-based retrospective cohort study. Aust N Z J Obstet Gynaecol. 2019.

13. Highley LL, Previs RA, Dotters-Katz SK, Brancazio LR, Grotegut CA. Cesarean delivery among women with prolonged labor induction. J Perinat Med. 2016;44(7):759-766.

14. Danilack VA, Hutcheon JA, Triche EW, Dore DD, Muri JH, Phipps MG, Savitz DA. Development and validation of a risk prediction model for cesarean delivery after labor induction. J Womens Health (Larchmt). 2019.

15. Tolcher MC, Holbert MR, Weaver AL, McGree ME, Olson JE, El-Nashar SA, Famuyide AO, Brost BC. Predicting cesarean delivery after induction of labor among nulliparous women at term. Obstet Gynecol. 2015;126(5):1059-68.

16. Guan P, Tang F, Sun G, Ren W. Prediction of emergency cesarean section by measurable maternal and fetal characteristics. J Investig Med. 2020:1-8.

17. Al-Qahtani S, Heath A, Quenby S, Dawood F, Floyd R, Burdyga T, Wray S. Diabetes is associated with impairment of uterine contractility and high Caesarean section rate. Diabetologia. 2012;55:489-498.

18. Gam CMBF, Larsen LH, Mortensen OH, Engelbrechtsen L, Poulsen SS, Qvortrup K, et al. Unchanged mitochondrial phenotype, but accumulation of lipids in the myometrium in obese pregnant women. J Physiol. 2017;595(23):7109-7122.

19. Hautakangas T, Palomäki O, Eidstø K, Huhtala H, Uotila J. Impact of obesity and other risk factors on labor dystocia in term primiparous 
women: A case control study. BMC Pregnancy Childbirth. 2018; 18(1):304.

20. Herstad L, Klungsøyr K, Skjærven R, et al. Elective cesarean section or not? Maternal age and risk of adverse outcomes at term: $A$

population-based registry study of low-risk primiparous women. BMC Pregnancy Childbirth 2016;16:230.
21. Levine LD, Downes KL, Parry S, Elovitz MA, Sammel MD, Srinivas SK. A validated calculator to estimate risk of cesarean after an induction of labor with an unfavorable cervix. Am J Obstet Gynecol. 2018; 218(2):254.e1-254.e7. 